\title{
PERFORMANCE OF AHI HOURLY AEROSOL OPTICAL PROPERTY DURING FREQUENT HAZE-FOG EVENTS: A CASE STUDY OF BEIJING
}

\author{
Qiangqiang $\mathrm{Xu}^{1}$, Xiaoling Chen ${ }^{1, *}$, Jian $\mathrm{Li}^{2}$, Jiadan Dong ${ }^{1}$, Tinghui $\mathrm{Li}^{1}$, \\ ${ }^{1}$ State Key Laboratory of Information Engineering in Surveying, Mapping and Remote Sensing, Wuhan \\ University, Wuhan 430079, China- (qiangqiangxu, xiaoling_chen, jiajiadong, litinghui) @ whu.edu.cn \\ ${ }^{2}$ School of Remote Sensing and Information Engineering, Wuhan University, Wuhan 430079, China- \\ lijian@whu.edu.cn
}

Commission III, WG III/8

KEY WORDS: Himawari-8, AHI, AOT, AERONET, Air Pollution

\begin{abstract}
:
The Advanced Himawari Imager (AHI) onboard Himawari-8, a next-generation geostationary meteorological satellite, provided firstly the full-disk aerosol observations every $10 \mathrm{~min}$ at sub-kilometer spatial resolution $(5 \mathrm{~km})$. This is responsible for retrieving the ground-level particulate matter of fewer than 2.5 micrometers and improving assimilation model. However, the representativeness of AHI L3 hourly Aerosol Optical Thickness (AOT) products remains unclear under different air quality conditions, Especially, over frequently polluted urban areas that feature complex surface characteristics and aerosol models. In this study, One-to-one comprehensive comparisons were conducted to evaluate the performance of three types of AHI L3 AOT products (version 3.0) based on the Aerosol Robotic NETwork (AERONET) aerosol measurements over Beijing. The overall comparisons of AHI and ground AOTs show the AHI merged AOT perform best, which the R is 0.87 , RMSE is 0.25 and $52.5 \%$ of retrievals fall within the envelope of Expect Error (EE, $\pm(0.05+0.2 *$ AOTground $)$ ). For the different primary pollutants, the results suggested the three types AHI hourly AOT products are more suitable for the fine particulate matters (PM2.5) retrievals, especially the merged AOT with 0.87 of R, 0.29 of RMSE and $58.8 \%$ of within EE. Furthermore, when the slight and moderate pollution happened over Beijing, the AHI hourly AOT products perform well. And when the heavy pollution happened, the performance of the AHI merge AOT and L2 mean AOT is better. a case during low to high pollution suggested that AHI merged AOT can capture the similar spatial pattern to the MODIS (Deep Blue) DB or (Dark Target) DTDB merged AOT and has good consistency with ground-based air quality monitoring. These results demonstrate the AHI hourly merged AOT is a promising aerosol retrieval for air quality.
\end{abstract}

\section{INTRODUCTION}

Tropospheric aerosols play a vital role in the earthatmosphere-ocean system, affecting climate by three crucial mechanisms. Firstly, the scattering of short-wave radiation and the absorption of solar radiation by aerosols themselves lead to direct radiative forcing, therefore cooling the climate system or changing the atmospheric circulation. Secondly, indirect radiative forcing occasions when aerosol particles interact with the cloud and alter cloud properties. Finally, aerosol particles can change indirectly the concentration of climate-affecting components, such as greenhouse gas (King et al. 1999). Exposure to aerosol particles for a long time also have an adverse impact on human health, especially fine aerosol particles from industries/urban emission. Moreover, ambient fine aerosol particles less than 2.5 micrometers have attracted public attention Because they can lead to several potential disease risks, such as respiratory, lung, cardiovascular diseases, even the neurological disorders (Schmidt 2019). However, ambient aerosols are difficult to quantify accurately due to the high spatial and temporal variability. This also makes it challenging to accurately evaluate its impact.

Since the short lifetime of aerosol and limited observation frequency of polar orbit satellites, MODIS is still difficult to capture the aerosol dynamic characteristics on a finer temporal scale (such as hourly or minutely). While Himawari 8, the next-generation geostationary orbit meteorological satellite launched the Japanese Meteorological Agency in October 2014, can observe the earth at a 10min frequency and sub-kilometer spatial resolution on the fixed location $\left(140.7^{\circ} \mathrm{E}\right.$ on the equator). This makes it possible to analyze the dynamic characteristics of aerosols. Based on the Level2 Aerosol Algorithm (Yoshida et al. 2018) and Level 3 Hourly Aerosol Algorithm (Kikuchi et al. 2018), the AHI official operational AOT products were released on July 2015, including L2 minutely and L3 hourly AOT products. Moreover, there are three types AHI hourly AOT products in official newly release L3 version 3.0 products: L2 mean AOT (average of L2 AOT for each pixel), pure AOT (L2 AOT with strict cloud screening) and merged AOT (spatiotemporal interpolation of pure AOT).

As a promising tool for monitoring ambient aerosol, since the release of AHI official operational AOT products in July 2015, many studied have been carried out based on these aerosol products. (Jin et al. 2019) identified and tracked a rapid-moving extreme dust event over east Asia by assimilating the Himawari-8 L2 AOT. (Yumimoto et al. 2018) applied the L3 hourly merged AOT as assimilation data to study the Heavy Siberian Wildfire Smoke in May 2016. (Dai et al. 2019) assimilated the 
Himawari-8 L 3 version 3.0 hourly merged AOT using the four-dimensional local ensemble transform kalman filter. (Wang et al. 2017) estimated the ground-level hourly PM2.5 concentrations based on the Himawari-8 L3 aerosol retrievals. (Zang et al. 2018) applied the principal component analysis-general regression neural network (PCA-GRNN) to estimate the hourly PM1.0 concentrations from AHI L3 aerosol optical thickness. Moreover, (Zang et al. 2019) carried out the estimation of china spatiotemporal PM1.0 distributions by combining PM2.5 observations with the AHI L3 AOT product. Although these studies have estimated the uncertainty of AHI AOT products, most of the spatiotemporal matching methods were like MODIS (the $20 \mathrm{~km}$ radius circle and $\pm 30 \mathrm{~min}$ ). Due to the high spatial and temporal variability of ambient aerosol and the different characteristics of polar and geostationary orbit satellites, and the AHI hourly aerosol retrievals algorithm has applied the spatiotemporal windows (12km, past 1hour) in newly released version 3.0 L3 AOT products, it is necessary to estimate the AHI L3 AOT products on an appropriate spatial and temporal scale. Furthermore, although the AHI hourly AOT products were introduced in the data assimilation model or used to derive the ground-level PM2.5/1.0 concentrations, it is still unclear about the performance of different AHI hourly AOT products under different air quality conditions, especially for the frequently polluted urban areas such as Beijing.

To address the questions above mentioned, in this study, we collected the newly release AHI L3 version 3.0 hourly AOT products from January to December 2018 because ( $\mathrm{Li}$ et al. 2019) confirmed it had more effective inversion after the version update. Additionally, the AERONET and surface air quality monitoring stations datasets also were collected for comparing and exploring the performance of three types AHI hourly AOT products under different air quality conditions. Furthermore, we compared the spatial pattern between MODIS and AHI AOT products during low to high pollution event. the main objectives in this study are to (1) evaluate the accuracy of three types AHI hourly AOT products-based quality assurance bit field for the purpose of selecting available data; (2) investigate the performance of the AHI hourly AOT products under different air quality conditions; (3) to figure out whether these AOT products are suitable for PM2.5 retrieval in frequent haze-fog regions such as Beijing.

\section{STUDY AREA AND DATA USED}

\subsection{Study Area}

Beijing is in the northwest boundary of the Northern China Plain and is encompassed by the Yanshan Mountains in the north and west. The climate of Beijing is a typical semi-humid continental monsoon climate in the north temperate zone, Influenced by the East Asia monsoon. Since 2012, frequent severe haze pollution events along with very high concentrations of PM2.5(over $500 \mu \mathrm{g} / \mathrm{m}^{3}$, also known as PM2.5 burst meter) have aroused public concern, due to the adverse effects on health. In order to alleviate serious atmospheric pollution, the Chinese government issued a three-year action plan to win the "Blue Sky Defense War" in 2018.

\subsection{AERONET Datasets}

The Aerosol Robotic Network (AERONET) is a ground-based network of sun photometers and sky scanning radiometers that are used to observe atmospheric aerosol optical properties with low uncertainty (less 0.01 0.02 ) and high temporal resolution ( $15 \mathrm{~min})$ without cloud contamination in a wide global range of locations, by measuring the extinction of direct solar radiation across the aerosol-loaded atmosphere (Holben et al. 1998). AERONET AOD characterizes a benchmark data source for the validation and bias-correction of various satellite AOD datasets (Charles et al. 2002, Levy et al. 2010). In this study, the recent Level 1.5/2.0 Version 3.0(cloudscreened and quality-assured) AOD datasets are used, from 4 sites in Beijing. The locations of Beijing sites are shown in Figure 1, including Beijing $\left(116^{\circ} 22^{\prime} 51^{\prime \prime} \mathrm{E}, 39^{\circ} 58^{\prime} 37^{\prime \prime} \mathrm{N}\right), \quad$ Beijing-CAMS $\left(116^{\circ} 18^{\prime} 59^{\prime \prime} \mathrm{E}, 39^{\circ} 56^{\prime} 1^{\prime \prime} \mathrm{N}\right)$ and Beijing_PKU $\left(116^{\circ} 18^{\prime} 35^{\prime \prime} \mathrm{E}, 39^{\circ} 59^{\prime} 32^{\prime \prime}\right)$ stations.

\subsection{Satellite Datasets}

Himawari-8/AHI can provide AOTs at $500 \mathrm{~nm}$ and Angstroms exponents between 400 and $600 \mathrm{~nm}$ with Level 2 and 3 schemes (L2, L3) coverage over about one-third of the Earth. L2 and L3 schemes represent minute-scale and hourly combined aerosol retrieval algorithm, respectively. Hourly combined retrievals (pure AOT and merged AOT) are AOTs with strict cloud-screening using differences in spatiotemporal variability characteristic of aerosol and cloud. The temporal resolution of L2 and L3 products is 10 minutes and 1 hour, respectively, with spatial resolution equal latitude-longitude gridding of 0.05 degrees. Detailed information about the L2 minute-scale and L3 hourly combined aerosol retrieval algorithm can be found in (Yoshida et al. 2018, Kikuchi et al. 2018), respectively. in this study, Level 3 version 3.0 aerosol products from January 2018 to December 2018 are obtained and used to analyze the comprehensive performance of AHI aerosol properties over Beijing with Heavy haze frequent events (AOT L2 mean, pure AOT, and merged AOT are selected).

For MODIS aerosol products over land, there are two algorithms on the current Collection 6.1(C6.1), namely, the (Dark Target) DT and (Deep Blue) DB algorithms. The MODIS operational aerosol parameters are provided at nadir spatial resolution of $10 \mathrm{~km} \times 10 \mathrm{~km}$ in level 2 datasets (MOD04 for Terra and MYD for Aqua) over various surfaces, except for ice/snow or inland water. Global validation shows more than $66 \%$ (on standard deviation) of DT retrievals falls within the uncertainty envelope of Expect Error $\left( \pm 0.05+15 \% * \mathrm{AOT}_{\mathrm{AERONET}}\right.$ ) (Levy et al. 2010). The uncertainty of DB retrievals is typical \pm $(0.05+0.2 *$ AOTMODIS) (Sayer et al. 2013). Due to the surface reflectance spectral relationship determination in DB algorithm is used the DT method on the vegetated region, there are new merged aerosol datasets combing the DT and DB retrievals based on the quality flag of DT and DB. In this study, MODIS DTBT merged AOT and DB AOT of Terra and Aqua satellites were obtained and analyzed to aerosol spatial distribution during low to high pollution events over Beijing. 


\subsection{Ground-based Air Quality Observations}

AERONET and satellite measure the aerosol amount in the entire atmospheric column, however, ground-based air quality stations monitor hourly surface PM2.5 and PM10 mass concentration, which are important parameters for air quality studies. In this study, three air quality monitoring stations near AERONET sites are selected, including WanLiu (matched Beijing_PKU), GuanYuan (matched Beijing_CAMS) and Olympic Sports Centers (matched Beijing). In order to validate the performance of satellites aerosol retrievals under different air quality situation over Beijing, the air quality monitoring data is used to characterize the air quality based on the Technical Regulation on Ambient Air Quality Index of China (HJ633-2012) during overpass of AHI and AERONET observation. The distribution of the three AERONET stations and air quality monitoring stations are shown in Figure 1.

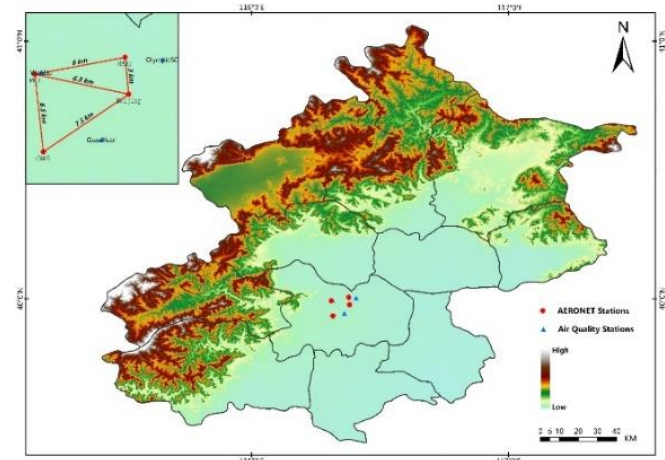

Figure1. Digital Elevation Model (DEM) image regarding AEONET (Aerosol Robotic Network) and ground air quality monitoring stations in Beijing; PKU:

Beijing_PKU site, CAMS: Beijing_CAMS site and RADI: Beijing_RADI site.

\subsection{Spatial and Temporal Collocation}

Unlike polar orbiting satellites (Terra and Aqua), only observing the same place twice a day. The nextgeneration geostationary satellite Himawari-8 (onboard Advanced Himawari Image, AHI senor) of the Japan Meteorological Agency can provide the 10-min temporal and sub-kilometer spatial resolution observations. While the ground-based point AERONET sun-photometers measures the continuous aerosol optical thickness (AOT) with a 15-min interval at each site. In order to consider the temporal and spatial differences of aerosol distribution simultaneously, in this paper, we carried out the one-toone comparison and validation between $\mathrm{AHI}$ and ground AOT, as (Kikuchi et al. 2018) mentioned in the hourly combined algorithm. Additionally, there are some validation statistic metrics as follow:1) the slope represents the systemic error of aerosol retrieval algorithm and the intercept indicates the error of surface reflectance estimate (Chu et al. 2002) 2) Pearson correlation coefficient (R), 3) root mean square error (RMSE), and 4) the fraction within the expected error (EE, $\pm\left(0.05+0.2 * \tau_{\text {AERONET }}\right)($ Chu et al. 2002$)$.

\section{RESULT AND DISCUSSION}

\subsection{Overall AHI and AERONET Aerosol Properties Comparison}

To validate the overall performance of AHI L3 hourly AOTs, we select different categories standard to analysis the performance by calculating various statistical metrics as mentioned above, including hourly aerosol products quality assurances flag which was provided by the JAXA Earth Observation Research Center(EORC)(https://www.eorc.jaxa.jp/ptree/documents /Himawari_Monitor_Aerosol_Product_v6.pdf). It is worth noting that only merged and pure AOT are provided the quality assurance by JAXA. In this study, the collocation results of AHI and AERONET in Beijing from January 2018 to December 2018 are almost not cloud contamination and solar/satellite zenith angle greater $70^{\circ}$ flags in the results of quality assurance flags of Merged and Pure AOTs, which most likely due to the strict cloud screening-out of the hourly combined algorithm. In addition, the pixels whose solar/satellite zenith angle was more than $70^{\circ}$ were possibly excluded in the hourly combined estimate. Therefore, to analysis the effects of different quality assurance flag for AHI aerosol products, in the condition of the very good result of AOT confidence (Bit Field:4-5), just these quality assurance flag values of surface reflectance confidence (Bit Field:11) and Angstrom exponent confidence (Bit Field:6-7) are used in this paper. Figure 2 compares AHI hourly combined AOTs against ground AOT for the resulting collocation dataset based on the quality assurances flag values of surface reflectance confidence. In figure 2, for the merged and pure AOTs with the very good surface reflectance confidence, which the result of surface reflectance bit field (11) is 0 or good, the correlation coefficients are all greater than 0.8 . However, for the no confidence, the correlation coefficients are less than 0.7. in terms of root mean square error represented the uncertainty of AHI retrievals, merged AOT with surface reflectance confidence is the best performance which the sample size is about 1080 and the RMSE is 0.28. In addition, the slopes of linear regression denote systematic biases if the deviation from 1 and the intercepts represent the errors in the surface reflectance estimates. Large errors in surface reflectance lead to large intercepts. In figure2, the intercepts with good surface reflectance are about 0.15-0.2 and decrease from Pure to Merged AOT. However, for no confidence, the intercepts are $0.23-0.24$. the results of figure 2 indicate the result of surface reflectance confidence bit field should be 0 or good in some application. Additionally, because the pure AOT is a subset of L2 AOT with strict cloud contamination screening and merged AOT derived from the spatial and temporal optimum interpolation of Pure AOT. The result indicates also the performance of merged AOT with good surface reflectance was improved by the spatiotemporal optimum interpolation in Beijing. Namely, the effect of surface reflectance estimated may be improved from pure to merged AOT by spatial and temporal optimum interpolation. Angstrom exponent (AE) is often used as a qualitative indicator of mean aerosol particle size in the measured column and really represents the slope of the aerosol spectral response. Therefore, the uncertainty of Angstrom exponent reveals the systematic error in the aerosol retrieval to some extent. Figure 3 shows the comparison between ground-based and AHI AOT with or without the AE confidence (Bit Field:6-7). 
In figure 3 , the slopes of Figure $3 \mathrm{a}$ and $3 \mathrm{c}$ (slope $=0.88,0.85$, closer to 1 ) are all greater than figure $3 \mathrm{~b}$ and $3 \mathrm{~d}$ (slope $=$ $0.71,0.68)$, respectively. This represents the AHI AOTs which the result of $\mathrm{AE}$ confidence bit field is 00 are better performance. Moreover, the results indicate also that the confidence of AOT and AE must have simultaneously same accuracy when selecting AHI AOT data, namely, the bit field results of AOT and AE confidence (Bit field:4-7) are all 00 . Therefore, in this study, we just use the best quality assurance AHI hourly AOT products which the values of quality assurance flag of pure and merged AOT is 0 or 1 , this means the results of quality assurance flags bit field of the L3 hourly combined aerosol products are all 0 , including all the quality assurance flags, except for data availability bit field.
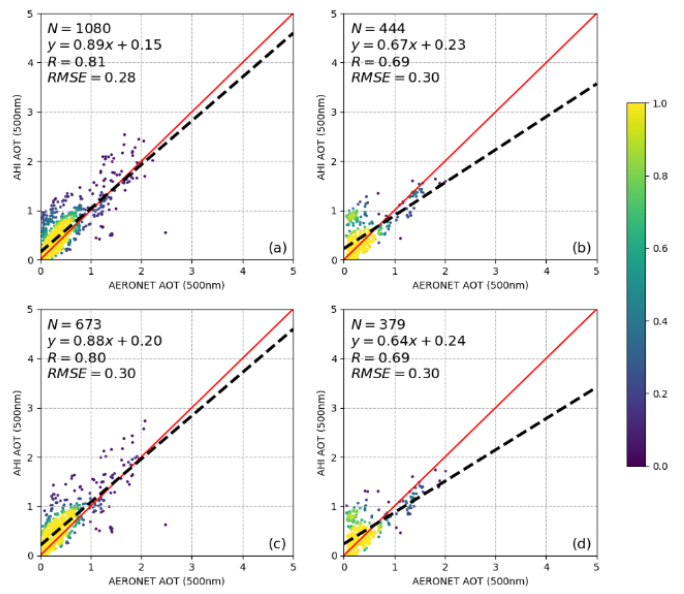

Figure 2. Comparison of AHI hourly combined AOTs against with AERONET AOT at 500nm in Beijing from January 2018 to December 2018 based on the quality assurance flag of surface reflectance confidence; the red solid line is the 1:1line and the black dashed line indicate the regression line.
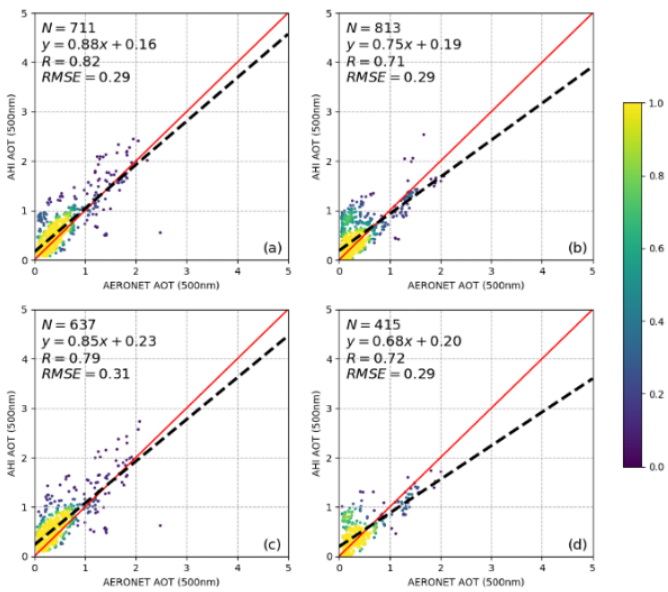

Figure 3. scatter density plots comparing AHI hourly combined AOTs against with AERONET AOTs at

500nm in Beijing from January 2018 to December 2018

based on the quality assurance flag of Angstrom exponent

There are three hourly aerosol products (AOT L2 mean, pure AOT, and merged AOT) provided by JAXA, L2 mean AOT is average of L2 AOT which has minimum quality control.in this study, based on the contents mentioned above, the pure and merged AOTs with the best quality assuranceare selected. In addition, we screen out the L2 mean AOT using the best quality assurance of merged and pure AOT.Figure 4 depicts the comparison of three hourly AOTs against ground AOTs in Beijing.Although the sample size of merged AOT and pure AOT are nearly identical $(569,637)$, Figure $4 d$ reveals the merged AOT is good consistency with ground AOT, which generate the correlation coefficient of 0.87 , the slope of 0.93 with the difference of 0.07 from 1 , the intercept of 0.1 closed to 0 , the RMSE is the least $(\sim 0.25)$ and the within envelope of expected error (EE) is 52.5\% ( theoretical value $\sim 68.3 \%$ indicates One standard deviation), For MODIS products, about $27.6 \%-47.7 \%$ of DT retrievals fallen within the envelops of expected error over Beijing(Tian et al. 2018). figure $4 \mathrm{~b}$ indicates the L2 mean AOTs with quality control have the similar to AOT merged performance, which has the RMSE of 0.28 , the R of 0.83 and the $49.0 \%$ falls within the envelope of EE. The results represent the $\mathrm{L} 2$ mean AOT and merged AOT with the quality assurance may all be selected for air quality or climate change. Therefore, unless otherwise indicated,In the following section, the L2 mean AOT usually represent the AOT screened using the quality assurance of AOT merged and pure.Moreover, the figure 4 a depicts the L2 mean with the minimum quality control may provide an aerosol field in some application, due to the more number of the sample (2777). In addition, in figure 4 there is about $30 \%-40 \%$ of three hourly collocation AOTs fellabove the envelope of EE. The results indicate AHI hourly aerosol products were overestimated in Beijing. Featuremore, we also discovered the about $35.3 \%$ of merged AOT falls above the envelope of EE which is the lest percentage in three AHI hourly AOT products.This reveals the spatialtemporal optimal interpolation may improve the overestimation in Beijing.
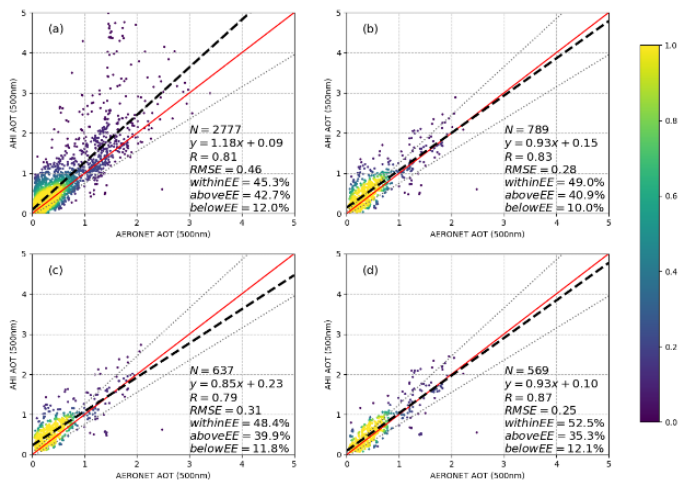

Figure 4. scatter plots of the comparison between the three hourly AOTs and AERONET AOT at 500nm over Beijing,

\subsection{Estimates Statistics of Hourly AOT under Different Air Quality Situations}

To estimate the uncertainty of AHI hourly AOT products under the different conditions of air quality, we select the three surface air quality monitoring sites as Figure 1 shown, including WanLiu(matched Beijing_PKU), GuanYuan(matched Beijing_CAMS) and Olympic Sports Centers(matched Beijing), which are closest to the collocation results of AHI and AERONET. Then we analyze the performance of the AHI hourly AOTs based on the primary pollutants and surface PM2.5 
concentration limits (described in the HJ 633-2012). Figure 5 depicts the successful retrieval counts of AHI L2 mean, merged, pure and AERONET AOT under the condition of different PM2.5 concentration. This result indicates that there are many successful retrievals when the slight and moderate pollution occurs, and the numbers of merged AOT are like the ground AOT under the different PM2.5 concentration limits situation. In addition, the AHI L2 mean AOTs have the largest retrieval counts and may provide an aerosol field in some application. Furthermore, in figure 5, when PM2.5 is greater than 200, namely the heavy pollution happened, AOT is rarely retrieved. In order to estimate the performance of AHI hourly AOTs in the condition of the primary pollutants of PM2.5 or PM10, we compared the AHI hourly AOTs against ground AOT base on the primary pollutants. In figure 6 , When the main pollutant is PM2.5, the results which the $\mathrm{R}$ is greater than 0.8 and more than $55 \%$ of retrievals falls within the envelope of EE, perform better. While the results of the primary pollutant of PM10 which the $\mathrm{R}$ is less than 0.6 is severely overestimated. Furthermore, in terms of accuracy, Whether PM2.5 or PM10 is the primary pollutant, the merged AOT performs best in the three AHI hourly AOT products, because the RMSE is less than 0.3.This indicates the AHI hourly AOT products may be more suitable for the fine particulate matter retrieval in air quality study, especially the merged AOT.

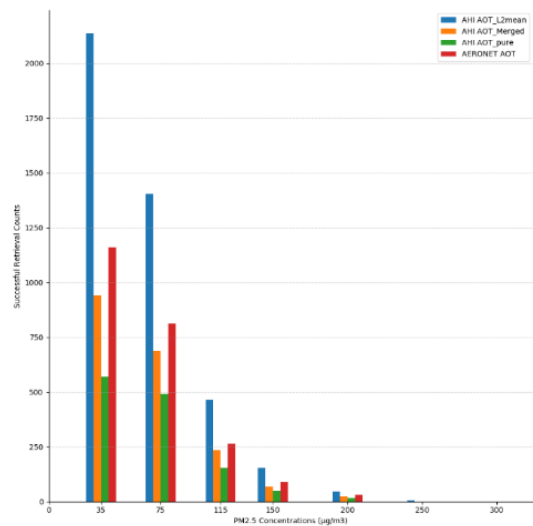

Figure 5. retrieval number histogram of AHI hourly AOTs and ground AOT under the condition of different PM2.5 concentration
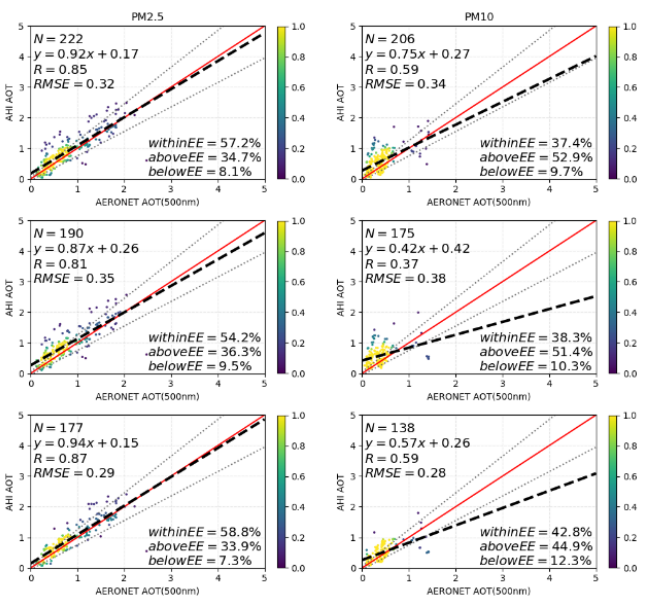

Figure 6. Scatter plots of comparing the AHI hourly AOTs and ground AOT under the different primary pollutants condition
For further estimate the performance of the AHI hourly AOT products under different PM2.5 concentration condition, in figure 7, we estimate the bias between AHI and ground AOTs. In general, a trend could be found in AHI AOT products, which the bias increase slowly from 0 to $100 \mu \mathrm{g} / \mathrm{m}^{3}$ and increase quickly after $100 \mu \mathrm{g} / \mathrm{m}^{3}$. For the merged AOT, the bias against ground AOT is less than 0.17 when PM2.5 concentration is less than $100 \mu \mathrm{g} / \mathrm{m}^{3}$ in figure $7 \mathrm{~d}$. The figure $7 \mathrm{c}$ depicts the difference between the pure and ground AOT is greater than 0.25 when PM2.5 concentration is more than $100 \mu \mathrm{g} / \mathrm{m}^{3}$. The bias of L2 mean AOT with quality control is more than 0.21 when PM2.5 concentration is greater than $100 \mu \mathrm{g} / \mathrm{m}^{3}$ in figure $7 \mathrm{~b}$. These results indicate the AHI hourly AOTs perform better when the moderate pollution occurs in surface monitoring. Furthermore, the retrievals of ground-level PM2.5 derived from satellites AOT are very useful for the air quality and public health application. The correlation between the satellites AOT and ground PM2.5 concentrations should be first carried out when determining which datasets may be more beneficial to air quality monitoring. Therefore, in order to estimate the performance of AHI AOT to derive the ground-level PM2.5, the AOT-PM2.5 relationships (including ground AOT) are shown in the figure 8. Figure 8 shows the merged and ground AOTs with the 0.35 of determination coefficients (R2) perform better than other AHI AOT products. For the MODIS AOD products, the determination coefficients are approximate $0.45(10 \mathrm{~km}$ DT AOD), 0.5 (3km DT AOD) and 0.6 (10 DB AOD) in Beijing (Chen, Fan and Yan 2017). This indicates that although (Kikuchi et al. 2018) has improved Hourly Estimates of AOT using spatiotemporal variability derived From Himawari- 8 geostationary satellite, the AHI retrievals still need further improvement for the applications of air quality.
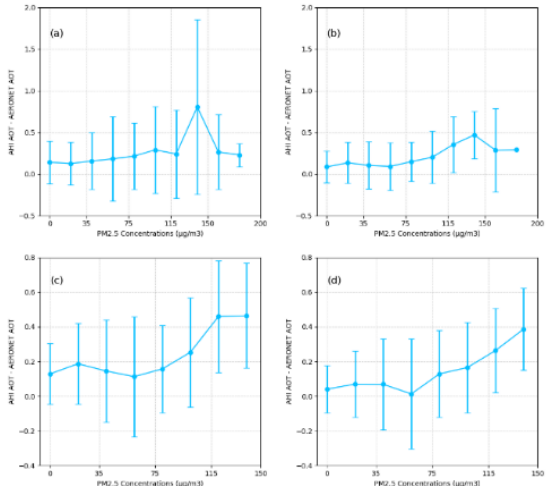

Figure 7. the bias between AHI AOTs and ground AOT under the different PM2.5 concentrations condition 

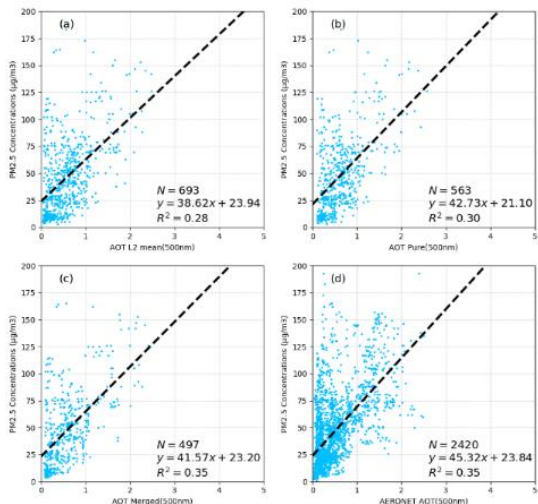

Figure 8. Correlation of the AOTs and PM2.5 concentrations

\subsection{Case of the Spatial Distribution Comparison AHI and MODIS Aerosol Products during Low to High Pollution Events}

According to the official report, in the conditions of the high humidity, the static and stable adverse meteorological factors, along with the affected by the early sand and dust retention, the northern china was suffering the heaviest pollution process this year from 29 November to 3 December 2018. Figure 9 depicts the pollution process by statistic histogram of PM2.5 concentration in Beijing. In this study, with the purpose of comprehending the performance of AHI retrievals during low to high pollutions events, we compared the spatial distribution between AHI merged AOT and MODIS AOT, along with the 35 sites of surface air quality monitoring on 30 November and 1 December 2018 in Beijing. The results are shown in figure 10,11 and 12 , respectively.

For the comparison, the MODIS (Terra and Aqua) true color images are selected in (a) and (b) of figure 10 and 11. The results of the true color images in figure 10 and 11 are well consistent with the figure 10 on 30 November (moderate pollution) and 1 December (heavy pollution) 2018. In figure $10 \mathrm{a}$ and $\mathrm{b}$, the heavy aerosol loading mainly located in the southeastern of Beijing and the thicker aerosol layer emerges and spreads to the surrounding in the afternoon (12:25 in local time, Aqua satellite transit time).the figure $10 \mathrm{c}$ and e depict there are a similar spatial pattern between the AHI merged AOT and MODIS DB AOT, such as the heavy aerosol loading can be even captured by the AHI and MODIS in the southeastern of Beijing as shown the figure 10a.Furthermore, AOTs of AHI and MODIS are good consistency with the surface air quality monitoring in some sites, such as in the south of Beijing with heavy aerosol loading. In addition, the figure $10 \mathrm{~d}$ and $\mathrm{f}$ show that the higher aerosols loading is captured by the AHI and MODIS retrievals including the heavy aerosols layer widespread diffusion, such as the Yanshan of west Beijing after 12:00 in local time, as shown in figure 10b.Moreover, we find the AHI retrievals show more coverage and better consistency with the ground point air quality measurements than the MODIS retrievals when the slightly and moderate pollution occurred.in figure 11, When the heavy pollution happened on 1 December 2018, the AHI and MODIS retrievals are missing to a certain extent. However, the AHI merged still provides better coverage. Furthermore, Figure 12 shows the AHI AOT products may provide dynamic monitoring for the air quality. Nevertheless, integration of AHI and MODIS AOT by combining the high Spatiotemporal Resolution of AHI and high accuracy of MODIS retrieval may better monitor air quality. in figure 10,11 and 12. Although the AHI and MODIS retrievals are well consistent with the most ground point observation, the values of 0 are found in some ground-based measurements, such as Xiangshan station. The result may be due to the instrument failure, if not, the values maybe not inconsistent with true color images from the (a) and (b) in figure 10 and 11. Furthermore, we may infer the value using the AHI aerosol retrievals.

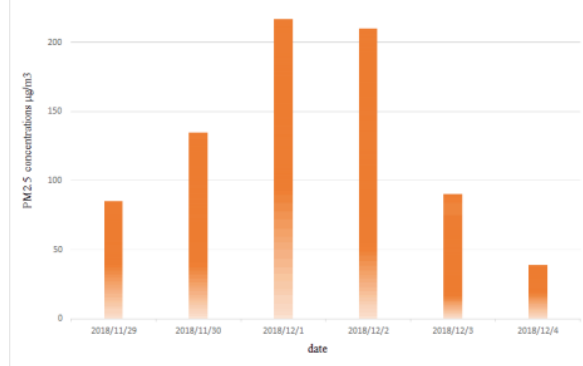

Figure 9. PM2.5 concentrations histogram of Beijing during the heavy pollution process from 29 November to 3 December 2018.

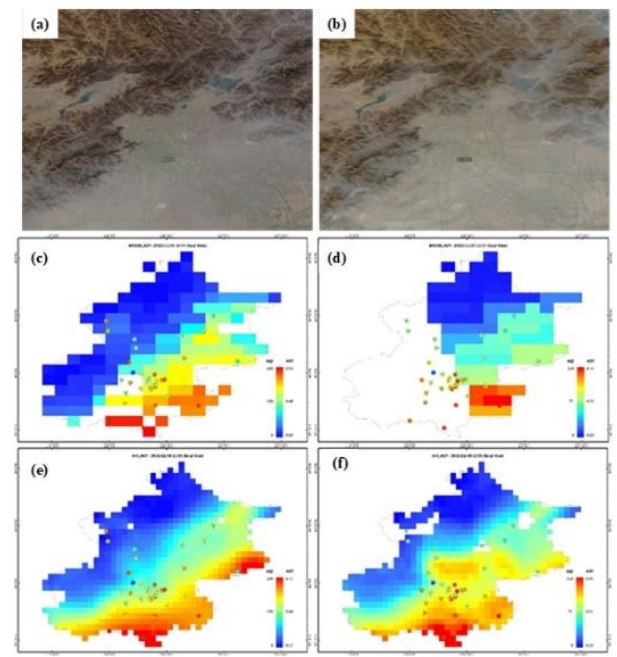

Figure 10.a case of spatial distribution of aerosol loading on 30 November 2018.

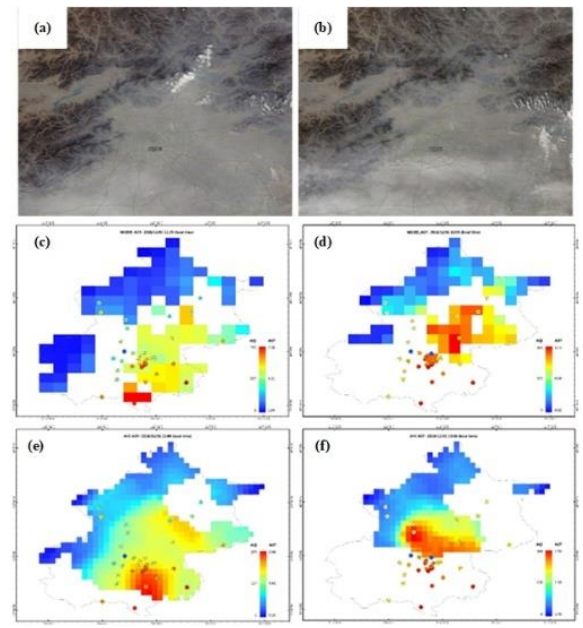


Figure 11. a case of spatial distribution of aerosol loading on 01 December 2018.
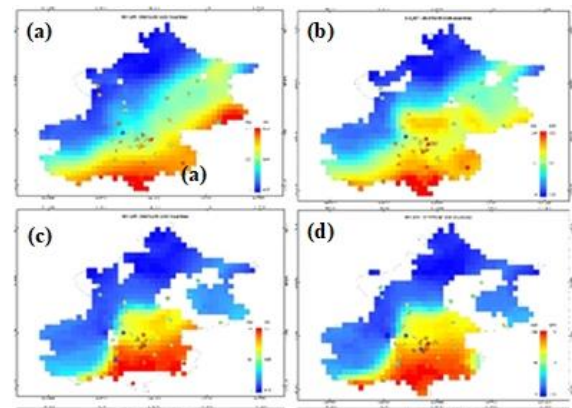

(e)
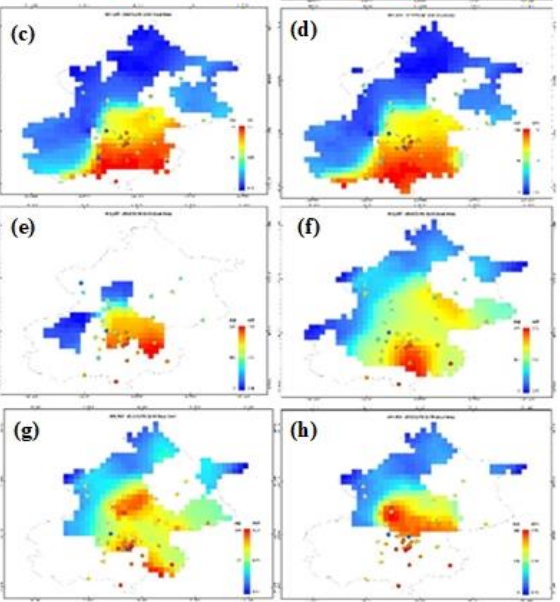

(i)

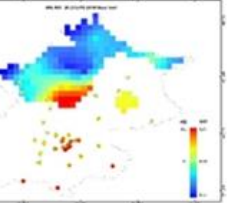

Figure 12. the dynamic pollution process of AHI merged AOT captured from 30 November 2018 (slight and moderate pollution), to 14:00 on 01 December 2018 (heavy pollution).

\section{CONCLUSION}

In this study, we comprehensively compared three newly released AHI L3 version 3.0 hourly AOT products (L2 mean, merged and pure AOT) against ground-based AOT and explored the performance of AHI hourly AOT products under different air quality conditions over the frequently suffered air pollution Beijing, in china. The comparisons based on the hourly aerosol product quality assurance flag provided by JAXA suggested that the AHI aerosol retrievals with the best quality control should be selected in some applications, such as air quality. In particular, the values of the quality assurance flag of the merged and pure AOTs must be 0 or 1, namely, the results of quality assurance flags bit field of the L3 hourly combined aerosol products are all 0 , including all the quality assurance flags bit field, except for data availability bit field. In the overall comparisons of three AHI hourly AOT products, the merged AOT is best consistent with ground AOT, which the R is 0.87, RMSE is 0.25 and $52.5 \%$ of retrievals fall within the envelope of EE. In addition, the L2 mean AOT screened by the quality assurance of merged and pure AOT also may be used in some applications, which the R is 0.83, RMSE is 0.28 and $40.9 \%$ of retrievals fall within the envelope of EE.

Under different air pollutants conditions, the results suggested the three types AHI hourly AOT products are more suitable for the fine particulate matters (PM2.5) retrievals, especially the merged AOT with 0.87 of R, 0.29 of RMSE and 58.8\% of within EE. Furthermore, when the slight and moderate pollution happened over Beijing, namely, PM2.5 concentrations are less than $115 \mu \mathrm{g} / \mathrm{m}^{3}$, the AHI hourly AOT products perform well. And when the heavy pollution happened over Beijing, the performance of the AHI merge AOT and L2 mean AOT with the quality control are better, which the bias against the ground is less than 0.4. In addition, a case during low to high pollution suggested the AHI hourly merged AOT is a promising aerosol retrieval and can capture the similar spatial pattern to the MODIS DB or DTDB merged AOT and have good consistency with ground-based air quality monitoring. Moreover, due to the more spatial and temporal resolution of AHI hourly AOT products( $5 \mathrm{~km}, 1$-hour), the AHI AOT products are more advantage than MODIS AOT and contribute to deduces air quality categories when groundbased air quality observations are limited or missing over large spatial scales. Certainly, if the high spatial-temporal resolution of AHI and the high accuracy of MODIS can be better integrated in the future, it will be better for the air quality study.

\section{ACKNOWLEDGMENTS}

The authors gratefully acknowledge NASA Goddard Space Flight Center for MODIS aerosol data from (https://search.earthdata.nasa.gov), and the Principal Investigators of AERONET sites that were downloaded from (https://modis-atmosphere.gsfc.nasa.gov/), and the team of the JAXA for their hard work. Research products of aerosol properties (derived from Himawari 8) used in this study were provided by Japan Aerospace Exploration Agency (JAXA) and National Institute of Environmental Studies

(NIES)

(http://www.eorc.jaxa.jp/ptree/index.html ).

\section{REFERENCES}

Ichoku, C., Chu, D. A., Mattoo, S., Kaufman, Y. J., Remer, L. A., Tanré, D., Holben, B. N, 2002. A spatio-temporal approach for global validation and analysis of MODIS aerosol products. Geophysical Research Letters, 29(12), MOD1-1-MOD1-4.

Chen, W., Fan, A., Yan, L, 2017. Performance of MODIS C6 Aerosol Product during Frequent Haze-Fog Events: A Case Study of Beijing. Remote Sensing, 9(5), 496.

Chu, D. A., Kaufman, Y. J., Ichoku, C., Remer, L. A., Tanré, D., Holben, B. N, 2002. Validation of MODIS aerosol optical depth retrieval over land. Geophysical Research Letters, 29(12), MOD2-1-MOD2-4.

Dai, T., Cheng, Y., Suzuki, K., Goto, D., Kikuchi, M., Schutgens, N. A., Nakajima, T., 2019. Hourly Aerosol Assimilation of Himawari- 8 AOT Using the Four Dimensional Local Ensemble Transform Kalman Filter. Journal of Advances in Modeling Earth Systems, 11(3), 680-711.

Holben, B. N., Eck, T. F., Slutsker, I., Tanre, D., Buis, J. P., Setzer, A., Lavenu, F., 1998. AERONET-a federated instrument network and data archive for aerosol Characterization. Remote Sensing of Environment, 66(1), $1-16$. 
Jin, J., Segers, A., Heemink, A., Yoshida, M., Han, W., Lin, H. X., 2019. Dust Emission Inversion Using Himawari-8 AODs Over East Asia: An Extreme Dust Event in May 2017. Journal of Advances in Modeling Earth Systems, 11(2), 446-467.

Kikuchi, M., Murakami, H., Suzuki, K., Nagao, T. M., Higurashi, A., 2018. Improved Hourly Estimates of Aerosol Optical Thickness Using Spatiotemporal Variability Derived from Himawari-8 Geostationary Satellite. IEEE Transactions on Geoscience and Remote Sensing, 56(6), 3442-3455.

King, M. D., Kaufman, Y. J., Tanré, D., Nakajima, T., 1999. Remote Sensing of Tropospheric Aerosols from Space: Past, Present, and Future. Bulletin of the American Meteorological Society, 80(11), 2229-2260.

Levy, R. C., Remer, L. A., Kleidman, R. G., Mattoo, S., Ichoku, C., Kahn, R., Eck, T. F., 2010. Global evaluation of the Collection 5 MODIS dark-target aerosol products over land. Atmospheric Chemistry and Physics, 10(21), 10399-10420.

Li, D., Qin, K., Wu, L., Xu, J., Letu, H., Zou, B., Li, Y., 2019. Evaluation of JAXA Himawari-8-AHI Level-3 Aerosol Products over Eastern China. Atmosphere, 10(4), 215 .

Sayer, A. M., Hsu, N. C., Bettenhausen, C., Jeong, M. J., 2013. Validation and uncertainty estimates for MODIS Collection 6 "Deep Blue" aerosol data. Journal of Geophysical Research-Atmospheres, 118(14), 7864-7872.

Schmidt, S., 2019. Brain Fog: Does Air Pollution Make Us Less Productive? Environment Health Perspectives, 127(6), 69003

Tian, X., Liu, Q., Li, X., Wei, J., 2018. Validation and Comparison of MODIS C6.1 and C6 Aerosol Products over Beijing, China. Remote Sensing, 10(12), 2021.

Wang, W., Mao, F., Du, L., Pan, Z., Gong, W., \& Fang, S., 2017. Deriving Hourly PM2.5 Concentrations from Himawari-8 AODs over Beijing-Tianjin-Hebei in China. Remote Sensing, 9(8),858.

Yoshida, M., Kikuchi, M., Nagao, T. M., Murakami, H., Nomaki, T., Higurashi, A., 2018. Common Retrieval of Aerosol Properties for Imaging Satellite Sensors. Journal of the Meteorological Society of Japan. Ser. II, 96B, 193209.

Yumimoto, K., Tanaka, T. Y., Yoshida, M., Kikuchi, M., Nagao, T. M., Murakami, H., Maki, T., 2018. Assimilation and Forecasting Experiment for Heavy Siberian Wildfire Smoke in May 2016 with Himawari-8 Aerosol Optical Thickness. Journal of the Meteorological Society of Japan. Ser. II, 96B, 133-149.

Zang, L., Mao, F., Guo, J., Gong, W., Wang, W., Pan, Z., 2018. Estimating hourly PM1 concentrations from Himawari-8 aerosol optical depth in China. Environment Pollution, 241, 654-663.

Zang, L., Mao, F., Guo, J., Wang, W., Pan, Z., Shen, H., Wang, Z., 2019. Estimation of spatiotemporal PM1.0 distributions in China by combining PM2.5 observations with satellite aerosol optical depth. Science of The Total Environment, 658, 1256-1264. 